\title{
CASA ORUGA, SANTIAGO, CHILE
}

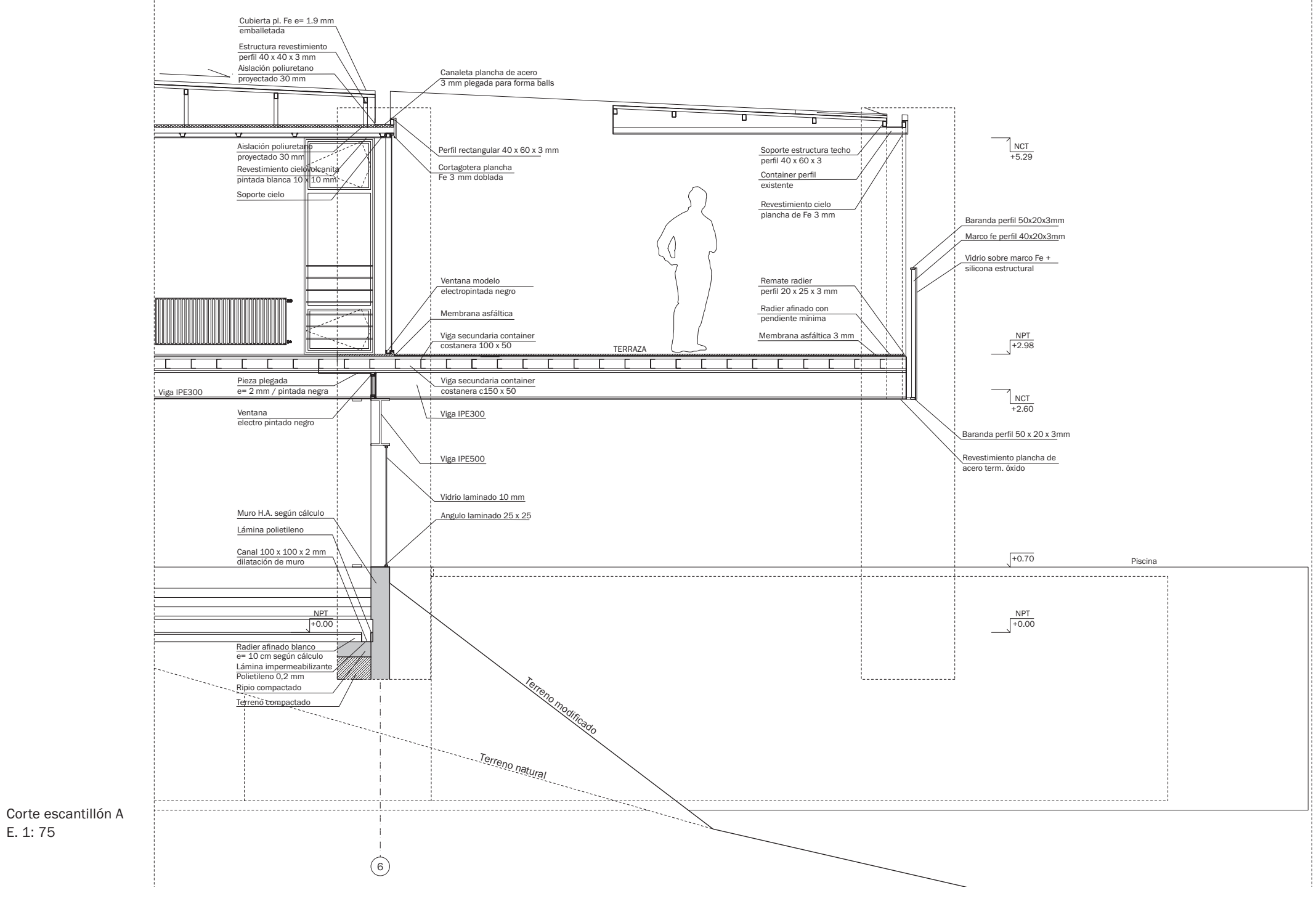

Sebastián Irarrázaval | Profesor, Pontificia Universidad Católica de Chile, Santiago

Arquitecto, Pontificia Universidad Católica de Chile, 1991; estudios de posgrado en Urbanismo, Architectural Association, 1993. Premio arquitecto joven destacado, AOA, 1999. Su obra ha sido expuesta en Santiago, Barcelona, Boston, Rótterdam y Venecia. Ha sido profesor invitado en la Universidad Central de Caracas, University of Arizona y Massachusetts Institute of Technology en Boston. Desde 1994 es profesor de la Pontificia Universidad Católica de Chile.
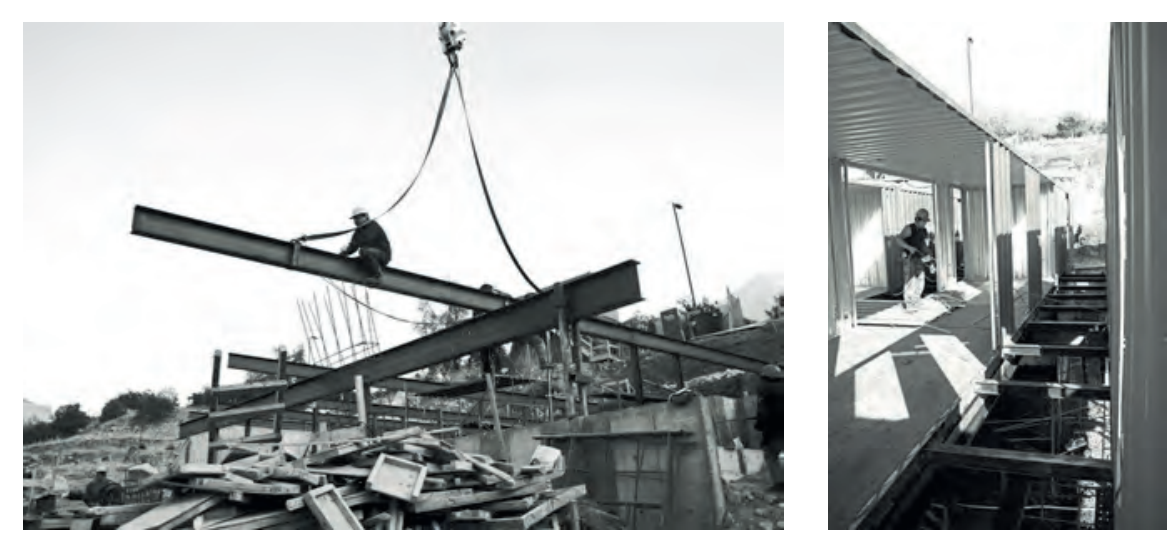
ARQUITECTO SEBASTIÁN IRARRÁZAVAL, 2012
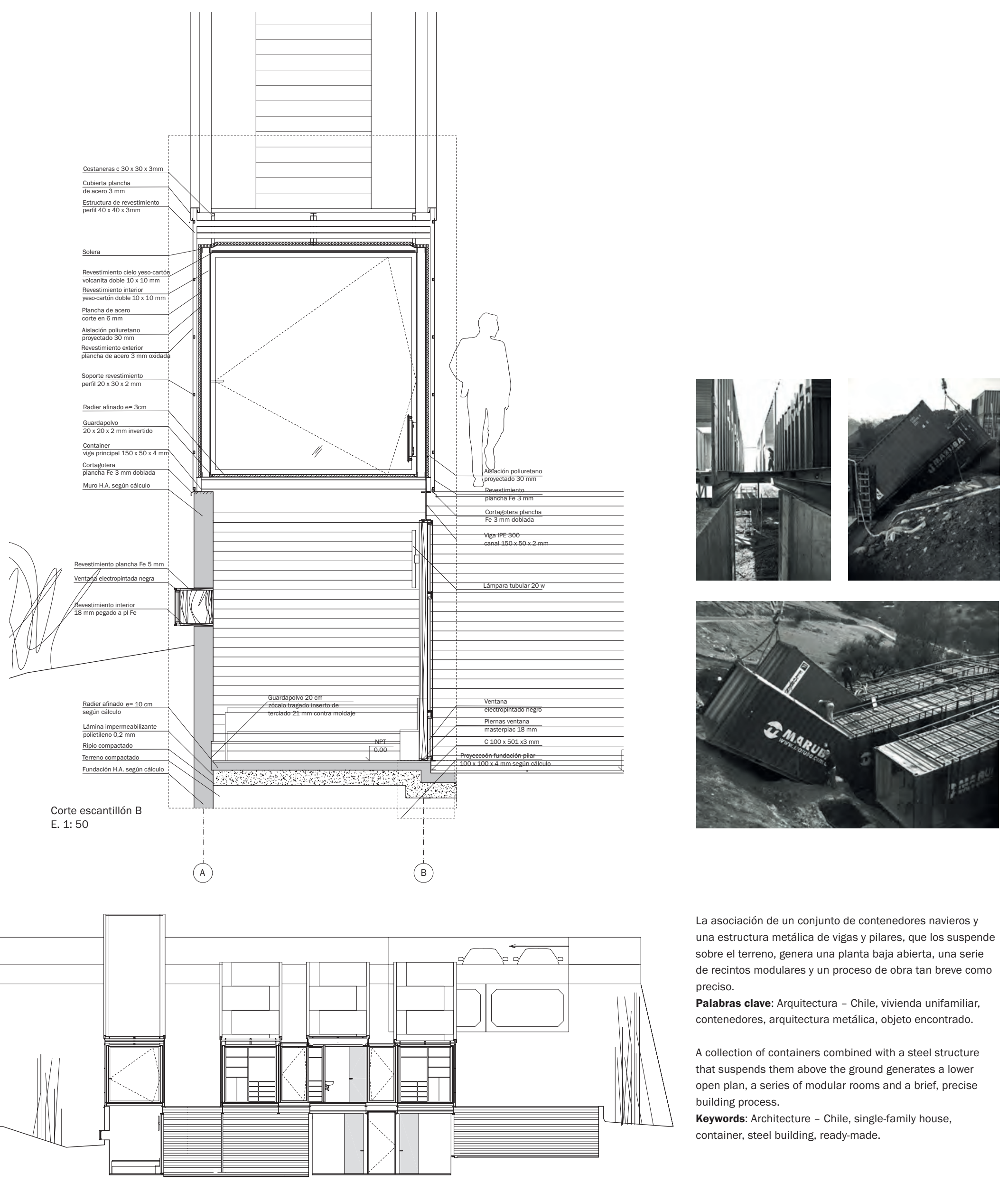

La asociación de un conjunto de contenedores navieros y una estructura metálica de vigas y pilares, que los suspende sobre el terreno, genera una planta baja abierta, una serie de recintos modulares y un proceso de obra tan breve como preciso.

Palabras clave: Arquitectura - Chile, vivienda unifamiliar, contenedores, arquitectura metálica, objeto encontrado.

A collection of containers combined with a steel structure that suspends them above the ground generates a lower open plan, a series of modular rooms and a brief, precise building process.

Keywords: Architecture - Chile, single-family house, container, steel building, ready-made. 
Corte BB
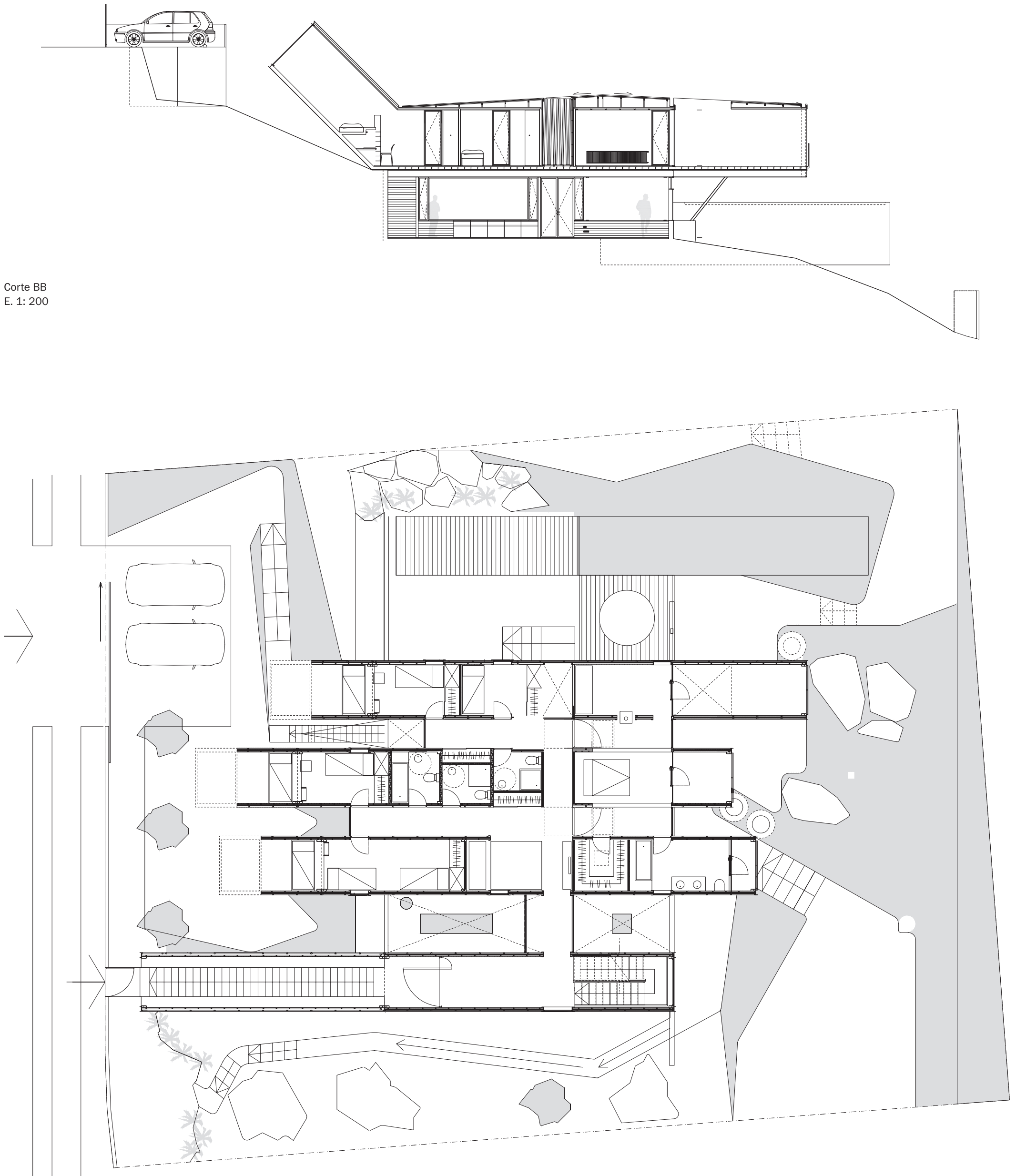

Planta nivel acceso +2.98

E. 1: 200 

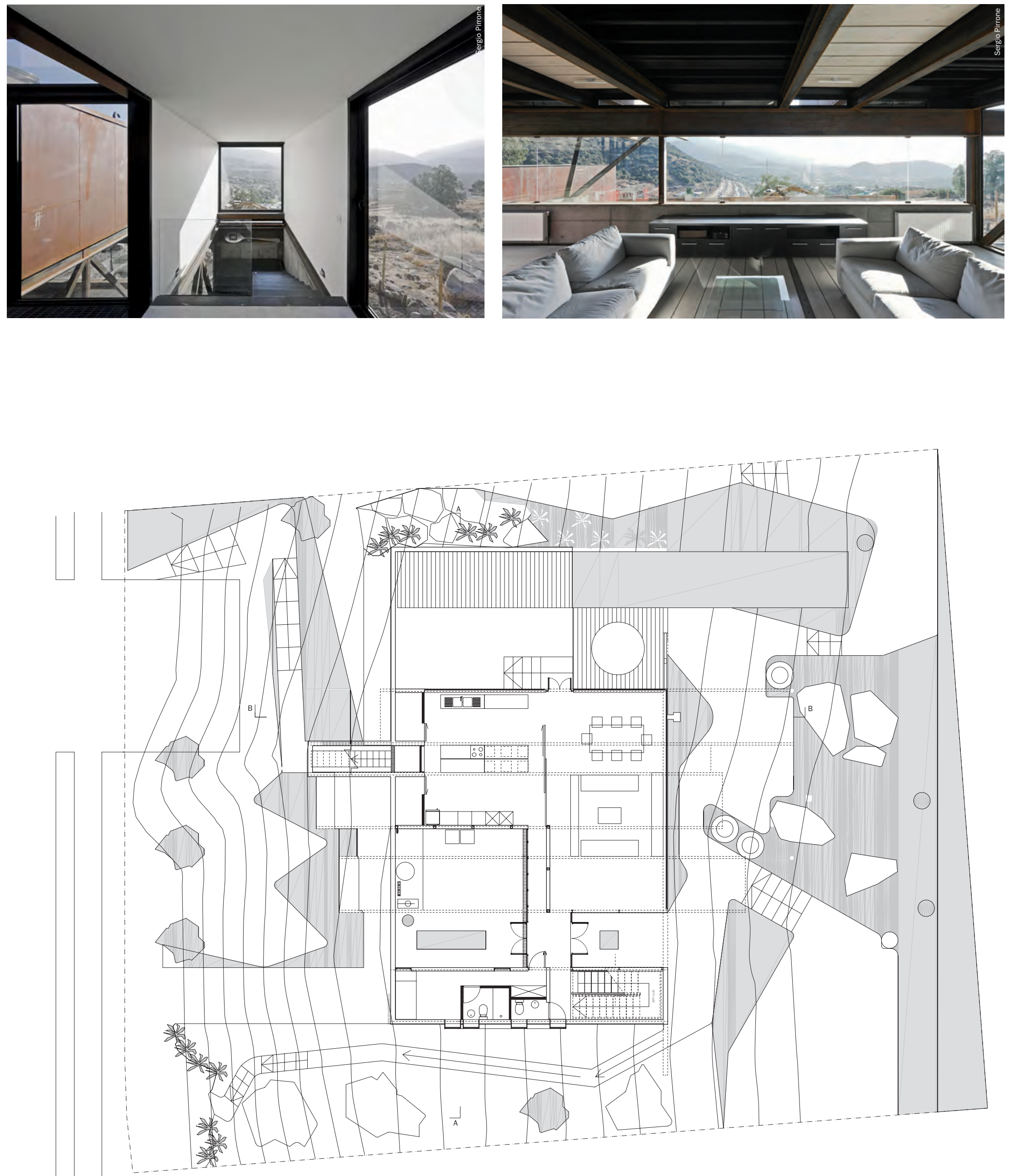

Planta nivel +- 0.00 


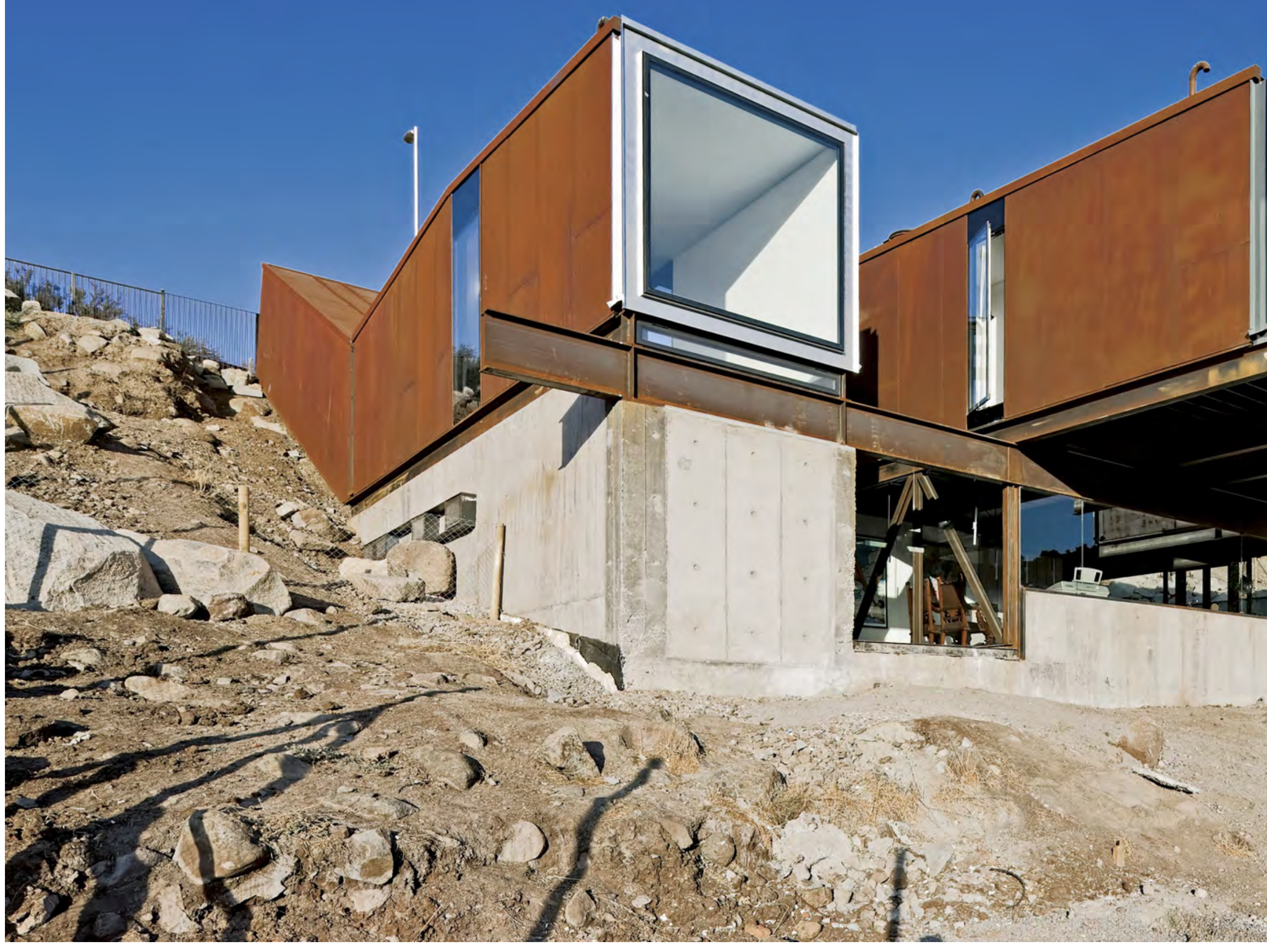




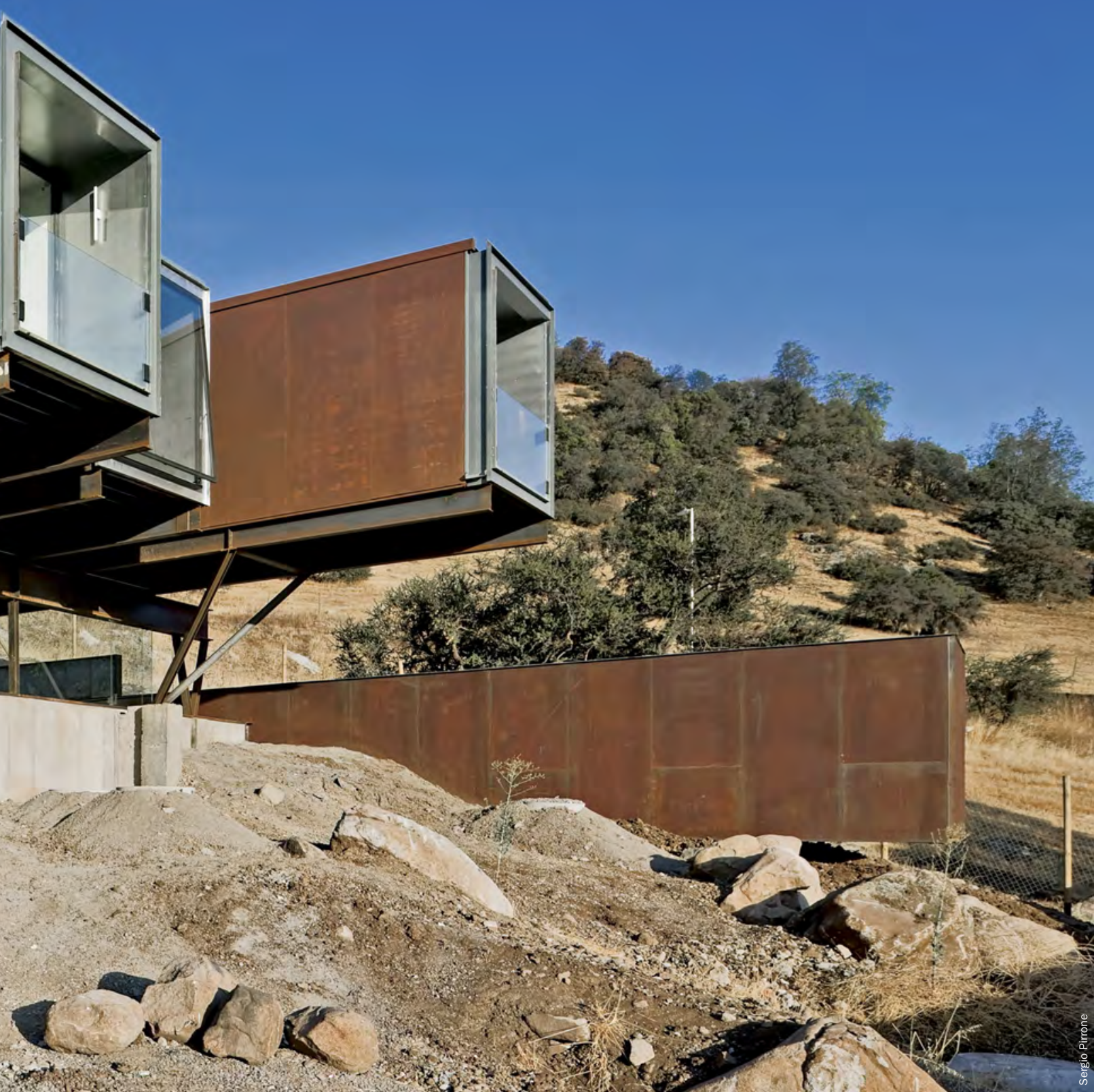

El proyecto consiste en una vivienda prefabricada construida en base a la reutilización y asociación de doce contenedores: cinco son contenedores marítimos de 40' estándar, seis corresponden a contenedores marítimos de $20^{\prime}$ estándar y el último es uno de 40' tipo open top, para la piscina.

Con el objeto de integrar el proyecto al territorio característico del pie de monte de la cordillera de los Andes, la vivienda se construye en base a franjas orientadas hacia el paisaje del valle; ellas se deforman a medida que se encuentran, perpendiculares, con la espalda que forma la pendiente del terreno. Como resultado de este acomodo de las piezas en el sitio, se generan el acceso a la casa y los lucernarios que coronan los dormitorios.

El esquema de franjas paralelas por el que se optó permitió crear intersticios que cumplen tres objetivos; organizar las circulaciones, promover la ventilación cruzada y generar estrechos encuadres hacia las vistas exteriores.

La construcción se realizó en etapas sucesivas, de las cuales la primera consistió en generar muros de contención para posibilitar una superficie horizontal que, en la base del terreno, hospedaría las zonas públicas de la vivienda. En segundo lugar y por sobre esta base, se montaron y ensamblaron los contenedores para albergar en ellos los dormitorios; por último, los contenedores se envolvieron con un manto mono material que, junto con integrar las partes, genera un piel ventilada que templa el interior. ARQ

\section{Bibliografía sugerida}

HOIDN, Barbara; BENEDIKT, Michael y Kevin ALTER (eds.). Latitudes. Architecture in The Americas. Center for American Architecture and Design - The University of Texas at Austin School of Architecture, Austin, 2012.

IRARRÁZAVAL, Sebastián. “Casa container 1". Revista ARQ № 75 - Casas. Ediciones ARQ, Santiago, 2011.

PALMER, Montserrat y Patricio MARDONES (eds.). Sebastián Irarrázaval. Ediciones ARQ, Santiago, 2009.

PING CHUA, Yen. "Sebastian Irarrázaval steels the show". MARK № 38. Frame Publishers, Ámsterdam, junio - julio de 2012.

CASA ORUGA | Arquitecto: Sebastián Irarrázaval Delpiano | Arquitecto asociado: Erick Caro | Ubicación: calle Manquecura, Lo Barnechea, Santiago, Chile | Cliente: Ricardo Bezanilla | Cálculo estructural: Pedro Bartolomé | Construcción: Sebastián Irarrázaval Arquitectos | Proyecto eléctrico: José Flores | Proyecto sanitario: Kenneth Page | Materialidad: doce contenedores marítimos de acero cortén, revestimientos exteriores en plancha de acero, muros de contención de hormigón armado | Presupuesto: US\$1.344/ $\mathrm{m}^{2}$; UF 28/m² | Superficie de terreno: $900 \mathrm{~m}^{2}$ | Superficie construida: $350 \mathrm{~m}^{2}$ | Año de proyecto: 2011 | Año de construcción: 2012 | Fotografía: Sergio Pirrone, archivo Sebastián Irarrázaval. 